\title{
Percepção vocal e qualidade de vida***
}

\author{
Vocal perception and life quality
}

\author{
Silvia Tieko Kasama* \\ Alcione Ghedini Brasolotto**
}

*Fonoaudióloga. Mestranda em Saúde na Comunidade pela Faculdade de Medicina de Ribeirão Prteo da Universidade de São Paulo. Endereço para correspondência: Avenida Elias Miguel Maluf 1-134 Bauru - São Paulo - CEP 17050-440 (silvia_kasama@yahoo.com.br).

**Fonoaudióloga. Doutora em Distúrbios da Comunicação Humana pela Universidade Federal de São Paulo. Docente do Curso de Fonoaudiologia da Faculdade de Odontologia de Bauru - Universidade de São Paulo.

***Pesquisa Realizada na Faculdade de Odontologia de Bauru da Univversidade de São Paulo.

Artigo de Pesquisa

Artigo Submetido a Avaliação por Pares

Conflito de Interesse: não

Recebido em 26.05.2006.

Revisado em 29.09.2006; 10.03.2007.

Aceito para Publicação em 10.03.2007.

\section{Abstract}

Background: the perception of dysphonia and the impact of vocal alteration on life quality. Aim: to verify if the interference of dysphonia on life quality is related to the vocal self-perception of dysphonic individuals and to the perception members of the community have about the vocal pleasantness of these individuals. Methods: 31 dysphonic adults, prior to treatment, filled out the Voice Related Quality of Life (V-RQOL) protocol that analyzes the impact of dysphonia on life quality. These individuals were also asked to comment about their self-perception of vocal quality. Recordings of the sustained "a" vowel and number counting from one to ten were made, using a digital system in an acoustic treated environment. The recorded material was presented to 25 judges, with no training in vocal perception, so that they could classify the voices according to the same scale used by the dysphonic individuals when commenting about their own voices. Results: according to Spearman's test, a statistically significant correlation was observed between the results of the V-RQOL and the vocal self-perception related to the social/emotional $(p=0.047)$, physical $(0=0.010)$ and total $(p=0.008)$ domains. However there was no correlation between the results of the V-RQOL and the perception of the judges, both for the sustained "a" vowel and for the number counting $(\mathrm{p}=0.475 \mathrm{e} p=0.152$ respectively). Conclusion: it was observed that the worst the opinion of the dysphonic individual about the impact of dysphonia on life quality, the worst was his vocal self-perception. A relationship between the life quality of the dysphonic individual and the vocal perception of listeners was not observed.

Key Words: Speech; Language and Hearing Sciences; Voice; Voice Disorders; Quality of Life.

\section{Resumo}

Tema: a percepção da disfonia e o impacto que a alteração vocal causa na qualidade de vida. Objetivo: verificar se a interferência da disfonia na qualidade de vida relaciona-se à autopercepção vocal do disfônico e à percepção da agradabilidade da voz desses indivíduos por pessoas da comunidade. Método: 31 adultos disfônicos, antes do processo terapêutico, preencheram o protocolo de Qualidade de Vida e Voz (QVV) que analisa o impacto da disfonia na qualidade de vida e opinaram quanto a autopercepção da qualidade vocal. Foram realizadas as gravações de vogal "a" sustentada e contagem de números de um a dez, utilizando sistema digital e ambiente acusticamente tratado. As emissões gravadas foram apresentadas para 25 juizes sem treinamento quanto à percepção vocal, para que classificassem as vozes segundo a mesma escala que os disfônicos utilizaram para opinar acerca de suas próprias vozes. Resultados: por meio do teste de Spearman, constatou-se que houve correlação estatisticamente significante entre os resultados do QVV e a autopercepção vocal, nos domínios social/emocional $(\mathrm{p}=0,047)$, físico $(\mathrm{p}=0,010)$ e total $(\mathrm{p}=0,008)$, porém não houve correlação entre os resultados do QVV e a percepção dos ouvintes leigos, tanto para vogal sustentada, como para fala encadeada ( $\mathrm{p}=0,475$ e $p=0,152$ respectivamente). Conclusão: Observou-se que quanto pior a opinião do disfônico sobre o impacto da disfonia em sua qualidade de vida, pior a sua autopercepção vocal, mas não observou-se relação entre a qualidade de vida do disfônico e a percepção vocal pelos ouvintes.

Palavras-Chave: Fonoaudiologia; Voz; Distúrbios da Voz; Qualidade de Vida. 


\section{Introduction}

Quality of life is a concept hard to define because it is considered subjective and multidimensional since it includes individual perception of physical, psychological and social status. After reaching consensus among specialists from several countries the World Health Organization (WHO) defined quality of life as "the individual's perception about his/her position in life, in the context of culture and system of values in which he/she lives and in relation to his/her objectives, expectations, standards and worries" (The WHOQOL Group, 1995).

Berlim and Fleck (2003) stated that quality of life has been widely used to determine the global impact of deceases and medical treatments, considering the patient's perspective.

Men is a social being and communication is the major responsible for development of interpersonal relationships. Berretin et al. (2001) mention that speech and voice are important in stablishing contact with the other and the world, by the exteriorization of feelings and thoughts.

According to Behlau et al. (2001a) there is euphonia if the voice presents good sound quality to the listeners and is produced without effort or discomfort by the speaker. Dysphonia occurs when the minimum traces of harmony and comfort are not reached. The author also states that these concepts are not as simple as they seem, because the concept of normality is very subjective and suggests the use of the expression adapted voice when "vocal production has socially acceptable quality, do not interferes with speech intelligibility, allows the individual's professional development, presents gender and age adequate frequency, intensity, modulation and projection and conveys the emotional content of the utterance".

Pinho (2003) points out that the term hoarseness should not be used as a synonym of dysphonia, since the different kinds of dysphonia are characterized by different acoustic patterns, diverse anatomic loci, different etiologies and hoarseness can be just the symptom of a more complex condition.

Several criteria can be used to classify dysphonias. The Behlau and Pontes classification system (Behlau et al. 2001) is based on the etiology of the vocal disorders. It suggests the classification of dysphonias in three groups: functional dysphonias (that can be primary functional disorders, due to the incorrect use of voice; secondary functional dysphonias, due to vocal non-adaptation and psychogenic functional dysphonias), organo-functional dysphonias (due to the association of organic and functional factors) and organic dysphonias (due to organic conditions and that can be sub-divided in organic dysphonias related to disorders on the communication organs and organic dysphonias related to other organs and systems).

Among all the types of dysphonia, the impact on vocal quality can vary widely, from discrete to severe. Dysphonia can even jeopardize the individual's professional success, as is the case of the professionals of the voice that depend on a specific vocal production and/or vocal quality to (Behlau et al, 2005).

As with quality of life, the impact of a specific health condition is hard to measure. Several researches had been dedicated to the development of measuring instruments for dysphonia and its impact. Jacobson et al (1997) built the Voice Handicap Index (VHI) that can be used to measure the effectiveness of vocal treatment techniques. Hogikyan and Sethuraman (1999) built an instrument to measure the relationship between voice and quality of life (V-RQOL - Voice-related quality of life). Gliklich et al (1999) built and validated a specific protocol to unilateral paralysis of vocal fold, the VOS (Voice Outcome Survey) to assess the global quality of voice and the selfevaluation of the impact of the vocal condition on every-day activities. Ma and Yiu (2003) reported the development of a form of evaluating the dysphonia perception, the limitation of activities and restriction of participation (VAAP - Voice Activity and Participation Profile). The VoiSS (Voice Symptom Scale) was developed and validates by Deary et al. (2003a) as a scale of vocal symptoms that reflect physical, communicative and emocional symptoms related to dysphonia in adults.

Nowadays there is a great interest in developing and applying measures of results based in the patient's opinion, as the quality of life and disadvantage indexes. The assessment of the disadvantage and response to treatment is applicable in the case of dysphonias due to the limitation of perceptual analysis and object studies of vocal function (Hogikyan and Rosen, 2002).

The Short-Form-36 (SF-36) was constructed to assess the health status on the Medical Outcomes Study (MOS). It consists of a questionnaire with 36 items with 8 sub-scales that include physical functionality, body pain, general mental health, 
emotional aspects (limitations due to mental disorders), vitality and general health perception (Ware and Sherbourne, 1992). The study from Wilson at al (2002) compared the self-perception of general health in dysphonic patients with a control group and examined the differential impact of dysphonia on the various areas of health through the application of the SF-36. They found that the dysphonic patients presented lower scores (indicating poorer health state) than the control group in all sub-scales of SF-36.

Some studies used these protocols that assessed the individual's opinion about the disadvantages that the vocal disorder produce in cases of specific dysphonias that frequently generate strong negative impact. Spector et al. (2001) found improvement on the score on the SF36 , IDV and VOS after surgical treatment to glottis insufficiency in patients with unilateral paralysis of vocal fold. Hartnick (2002) adapted the VOS to care takers of children and adolescents and concluded that patients with tracheotomy showed more disadvantage when compared to those with decanulization surgery. Hogikan et al (2001) observed significant improvement on the responses to the QVV in patients with spasmodic abduction dysphonia after the first shot of botulinum toxin. Benninger et al. (2001) found significant improvement on the three sub-scales and on the total score of the IDV of patients with spasmodic abduction dysphonia after two to four weeks of treatment with botulinum toxin shots. The quality of life analysis also became important instruments to the assessment of larynx cancer treatment (Weinstein et al., 2001; Meleca et al., 2003).

Teachers are professional with great chances of presenting vocal problems related to the profession's high vocal demand and lack of knowledge about vocal care. Many studies showed that the lack of knowledge about their own voice is very common among teachers (Ferreira, 2001; Carelli e Nakao, 2002; Ferreira et al., 2003, Schwarz e Cielo, 2005). Penteado (2003) studied the relation between teachers' quality of life and vocal health using quantitative (QVV e World Health Organization Quality of Life- WHOQOL/ short) and qualitative methods (focal groups). It was observed that the general health of teachers is jeopardized by several physical and emotional conditions and unresolved general and voice health problems, concluding that health care programs specific designed to teachers are important. Grillo and Penteado (2005) applied the QVV in 120 teachers of fundamental public schools. The analysis of results included the QVV total score, the descriptive analysis of questions and the determination of Spearman's correlation coefficient between total score and question about how perceives the voice, age, time of teaching and daily working hours. The average total score was 84,2 and $49,2 \%$ perceived their voices as good despite reporting difficulties to speak. They concluded that the impact of voice on quality of life and work is still little perceived by teachers that have high vocal demand and need health promotion programs.

The perception of voice quality is a subjective parameter. It is based on comparisons with other voices or previous impressions of the hearer about the voice. Besides it involves several factors as personality characteristics, psychological factors and experience with voice analysis (Bele, 2005). Studies about perception of voice quality by experienced professionals are frequent and important to the investigation of different voice disorders. But the perception of his/her own voice by subjects with voice disorders and the perception of people without experience on the study of the human voice are also relevant.

Murry et al (2004) used the V-RQOL with dysphonic patients (before treatment) and in individuals without complaints about their voices. The voices of both groups were also assessed by speech and language pathologists using a perceptive-auditory scale (GRBAS). The term GRBAS refers to Grade $(\mathrm{G}$, that represents the degree of voice disorder), Roughness (R, irregularity on the vibration of vocal folds), Breathiness, Asteny and Strain. The perception of voice severity by professionals and the perception of voice related to quality of life of dysphonic persons presented moderate relationship, what suggests that factors, other than those directly related to vocal quality may contribute to influence the individuals' opinions.

Vocal self evaluation or self perception has been greatly recognized because it tries to detect the subject's perception of his/her own voice. Because it is a subjective measure, it is widely used in comparison with objective measures taken during assessment. There are several ways to measure it: through questions, multiple choice alternatives and visual analogical scale, as proposed on the Dejonckere et al's protocol (2001).

Self perception of vocal quality can be influenced by personality and by psychological factors. Deary et al (2003b) conducted a study with 
the objective of analyzing the relation between objective and subjective measures of voice quality and psychological factors in patients of voice therapy. They applied a questionnaire composed of questions that assessed vocal self perception, a vocal profile scale, specific questionnaires to assess personality characteristics and the SF-36. Patients with more psychological factors and poorer quality of life reported worse vocal quality.

Eadie and Doyle (2004) found a moderate correlation between responses of laryngectomized individuals to the HNQOL (Head and Neck Quality of Life), an instrument built in the Michigan University and that analyses functional and emotional aspects of patients with head and neck cancer and the evaluation of traqueo-esophagyc speech of these patients by inexperienced judges.

It is known that dysphonia may interfere in the quality of life, but there are few studies that relate vocal self perception with quality of life. Besides a study relating the perception of persons that live with dysphonic persons and the social function of voice would be of great importance.

This knowledge may help actions with the dysphonic individual, once the self perception and vocal psychodynamic are important factors of the therapeutic process.

In this study the objective was to verify if the interference of dysphonia on the quality of life is related to the vocal self perception of the dysphonic individual and to the perception of the voice quality of these individuals by persons of the community.

\section{Method}

The project of this research was approved by the Research and Ethics Committee of the institution with protocol number 47/2003. After reading an information letter explaining the research's objective and procedures the participants were asked to sign the approved consent form. All the involved subjects consented with the realization of this research and publication of its results, according to the resolution 196/96.

Data were gathered in the Language and Speech Clinic of a university service (FOB-USP). The inclusion criteria to participate in this research were: attend regularly to the clinic, not present any other communication disorder besides the dysphonia, have at least 18 years of age and still have not started the therapeutic process. The sample was composed of 31 individual of both genders, being four men and 27 women between
18 and 72 years, with average age of 38 years. Of this sample, nine were active and two were retired teachers of various grades, from fundamental school to university. Among the professionals that depend on their voices to work, besides the active teachers there was a guitar teacher, a karate teacher and a salesman. /the other participants were housewives, retired, students and administrative professionals.

To meet the criteria of conducting the study before the individual started the therapeutic process the procedures were conducted during the first visit of the patient to the clinic, when the dysphonia was detected but the diagnostic procedures were still not concluded. The posterior access to the data of the patients provided information about the classification of the dysphonia of 21 participants of the study. Nine were cases of functional dysphonia secondary to vocal in-adaptation, five had primary functional dysphonia due to incorrect use of voice, four had organic-functional dysphonia, two were organic dysphonias and one was a case of functional dysphonia due to psychogenic disorder. The other participants didn't initiate or didn't conclude the diagnostic procedures due to schedule unavailability, moving, obtaining services in other places or lack of data as telephone or address.

Patients were asked to fill the protocol of Quality of Life and Voice (V-RQOL) proposed by Hogikyan and Sethuraman (1999), translated and adapted to the Portuguese by Behlau (Behlau et al, 2001b), which analyses the impact of dysphonia on the subject's quality of life. The questionnaire has 10 items that include physical functionality and socioemotional control. The answering scale include "never happens and is not a problem", "seldom happens and is rarely a problem", "sometimes happens and is a moderate problem", "happens frequently and almost always is a problem", "always happens and is a bad problem". These responses are numbered from one to five, respectively. The following instructions were provided to the participants: "To answer the questionnaire, consider the severity of the problem as well as its frequency, evaluated each of the items according to the scale presented". The sum of the responses was conducted as suggested by the authors. The result may vary from zero to 100 and the higher results indicated better quality of life.

The total score is provided by the sum of all answers. The social-emotional control is presented on questions 4, 5, 8 and 10 and the domain of physical functionality is presented on the questions 
$1,2,3,6,7$ and 9 . It is, therefore possible to determine the isolated scores of each domain.

This instrument was chosen is due to the fact that its application is fast, it is simple to the adult individual to respond and it is effective to the aim it is proposed.

Besides the sum of each domain the total value of each question of the V-RQOL was determined by multiplying the answer's value (one to five) by the number of occurrences and the sum of these values.

The participants were also questioned about the self perception of voice quality through a scale from one to five. "1" represents self perception of excellent voice; "2" a very good voice; "3" a good voice"; "4" a reasonable voice and "5" a bad voice. The procedure of voice self evaluation, including the scale score was the same used in the validating study of the V-RQOL by Hogikan and Sethuraman (1999).

The patients' voices were recorded by posterior evaluation by 25 individuals without training about vocal perception. This group of individuals, responsible for the judgment of voices was composed of participants of both genders (24 female and 1 male), all students of the second under graduation year of speech and language pathology with ages varying from 18 to 22 years (average 19.8). These individuals were considered untrained because they had no formal prior experience judging vocal quality. A digital system was used, with M2-R70/Sony recorder and microphone HD74/ LeSon. Recordings were conducted in silent acoustically treated environment. The emission of sustained "a" was asked for three consecutive times followed by counting from 1 to 10 . The microphone was positioned on a 450 degree angle at five centimeters from the subject's mouth who was seated during the recording.

The emission of sustained "a" was asked for three consecutive times but onle one emission was presented to the judges. The editing criteria was the choice of the first emission or, if there was a failure on it (patient didn't proceed correctly or there was any kind of interference), the second emission and, if by any chance, there was any trouble with it, the third one.

To present the recordings to the judges they were reproduced on a mini-disc device (MD) M2R70/Sony with a loudspeaker Ciclotron, model cube 90. It was explained to the judges that they would be participating on a scientific research and they should express their opinion about some voices. Two protocols were prepared, one for the 1 to 10 counting and the other to the sustained vowel "a" emission, with the number of voices to be appreciated (1 to 31 ) and the same evaluation criteria of voice self perception: "excellent", "very good", "good", " reasonable" and "bad". The judges were asked to sign on one of the criteria on the line correspondent to the subject. First the counting was judged and then the sustained vowel. This process was conducted in periods that didn't exceed one hour of duration. Afterwards the average value of each participant by the 25 judges was determined.

By means of the Spearman's correlation coefficient the correlations of the results on $\mathrm{V}$ RQOL, the self perception question and the listener's analysis were determined, The Wilcoxon test was used to verify if the difference between the score on social emotional domain and on physical domain was statistically significant. The significance degree of $\mathrm{p}<0.05$ was used for both tests.

\section{Results}

The V-RQOL scores can vary from zero (poorer) to 100 (better), that means, higher scores indicate better quality of life.

The average scores on V-RQOL in the socio emotional domain and physical functionality were 75.19 and 64.08 respectively. The total score of the 31 patients was 68.55 .

The average scores on the socio-emotional and phisical domains were compared by means of the Wilcoxon test with the score on the socio-emotional domain statistically higher than on the physical domain $(\mathrm{p}=0.01)$.

Data referring to the self perception of vocal quality of the 31 participants show that non of them consider his/her own voice as excellent or very good and in the opinion of the judges non of the voices was considered excellent during the sustained "a" vowel.

The values of scores on each domain of the VRQOL, of self perception of vocal quality and of judges' perception are presented on Table 1.

On Table 2, to verify if there is a correlation between the scores on V-RQOL, vocal self perception and the opinion of non-specialized listeners the Spearman's correlation test was used ( $p<0.05$ ). It was found a negative (observed by the $\mathrm{R}$ value) and statistically significant correlation between the scores of the different domains of the V-RQOL (physical, socio-emotional and total) and vocal self-perception. Since the classification 
criteria scale of vocal self perception has a decreasing quality referent ("1" means excellent and "5" means bad), the higher the scores on VRQOL, better is the classification of vocal quality self perception.
There was a positive and statistically significant correlation between the domains of the V-RQOL (total score, physical domain and socio emotional domain).

There was no correlation between the scores on the V-RQOL and the judgment by the judges neither between the judges' opinions and the self perception of dysphonic individuals.

TABLE 1. Score on V-RQOL and on perception of voice quality by participants and judges.

\begin{tabular}{lccccc}
\hline & Average & Mean & Minimum & Maximum & Standard deviation \\
\hline V-RQOL/Emotional $^{1}$ & 75.19 & 75 & 12.5 & 100 & 23.69 \\
V-RQOL/Phisical $^{1}$ & 64.08 & 66.6 & 8.3 & 100 & 24.90 \\
V-RQOL/Total $^{1}$ & 68.55 & 70 & 12.5 & 100 & 22.34 \\
Selfperception $^{2}$ & 3.84 & 4 & 3 & 5 & 0.73 \\
Judges/ encadeated speech $^{2}$ & 3.37 & 3.44 & 1.48 & 5 & 1.08 \\
Judgess/ sustained "a" $^{\text {" }}$ & 3.46 & 3.36 & 1.96 & 5 & 0.87
\end{tabular}

1-The higher the score the better the quality of life

2 -The higher the score, the worst the opinion about vocal quality

TABLE 2. Correlation between the V-RQOL, self perception and judgement by non-expert judges

\begin{tabular}{ccc}
\hline Pairs of variables & Spearman's $\boldsymbol{R}$ & p-level ( Spearman's correlation) \\
\hline V-RQOL Socio-emotional / encadeated speech judgment & -0.18 & 0.343 \\
V-RQOL Socio-emotional / Vowel judgment & -0.25 & 0.178 \\
V-RQOL Physical / encadeated speech judgment & -0.29 & 0.111 \\
V-RQOL Physical / Vowel judgment & -0.09 & 0.629 \\
V-RQOL Total / encadeated speech judgment & -0.26 & 0.152 \\
V-RQOL Total / Vowel judgment & -0.13 & 0.475 \\
Self perception / encadeated speech judgment & 0.34 & 0.064 \\
Self perception / Vowel judgment & 0.07 & 0.711 \\
V-RQOL Socio-emotional / Self perception & -0.36 & $\mathbf{0 . 0 4 7}$ \\
V-RQOL Physical / Self perception & -0.46 & $\mathbf{0 . 0 1 0}$ \\
V-RQOL Total / Self perception & -0.47 & $\mathbf{0 . 0 0 8}$ \\
V-RQOL Physical / V-RQOL Socio-emotional & 0.48 & $\mathbf{0 . 0 0 6}$ \\
V-RQOL Physical / V-RQOL Total & 0.92 & $\mathbf{0 . 0 0 0}$ \\
V-RQOL Sócio-emotional / V-RQOL Total & 0.76 & $\mathbf{0 . 0 0 0}$
\end{tabular}




\section{Discussion}

The V-RQOL protocol has simple application, is sensible to the influence of dysphonia on quality of life and is a good method to evaluate the results of treatments. Nevertheless there are few studies reporting its results.

In the present study the average of the total score on V-RQOL was 68.55; on the socio-emotional domain it was 75.19 and on the physical domain it was 64.08. These scores are similar to those reported by Murry et al (2004) in a study with 50 dysphonic subjects that obtained total score of 79.5 , socioemotional domain of 81.5 and physical domain of 62.4. In the study of V-RQOL validation to dysphonic individuals performed by Hogikyan and Sethuraman (1999) the average results obtained were 53.5 to the total score, 55.9 to the socio-emotional domain and 51.9 to the physical domain. The scores found by the same study on a population without vocal complaints averaged 98 to total, 98.8 to socioemotional domain and 97.3 to physical domain. In our sample we observed lower scores on the VRQOL when compared to the scores of the population without disorders of this other study. It suggests that there is a poorer quality of life associated to dysphonia. The lowest average score was also found in patients with abduction spasmodic dysphonia during the pre-treatment period in the study by Hogikyan et al (2001) (total score 28.68, socio-emotional score 29.76 and physical domains score 27.95). It should be stressed that these scores are influenced by the severe impact of the abduction spasmodic dysphonia on the voice quality, besides tha social and emotional limitations associated to the communication impairment.

The complaints involving the physical domain of V-RQOL were more frequent than the complaints associated to the socio-emotional domain. It can be observed in the average scores. Some studies using the VHI, other protocol that assesses the interference of voice disorder in every-day life activities also point to higher number of complaints of dysphonic patients in the physical sub-scale, when compared to the other two sub-scales (functional and emotional). This data can be observed in a study of patients with abduction spasmodic dysphonia in the period prior to treatment (Benninger et al. 2001) and of patients with unilateral vocal fold paralysis during the pretreatment period (Spector et al. 2001).

Based on the observation of the value associated with each question of the V-RQOL it should be noted that the complaints 1: "I have difficulty to speak strong (loud) or to be heard in noisy environments" and 2: "The air finishes fast and I must breath many times while I speak" were the most frequent of all complaints, being both of the physical domain. The complaints that mostly distress the patients in the socio-emotional domains were 4: "I get anxious or frustrated (because of my voice)" and 5: "I get depressed (because of my voice)". The analysis of the most frequent questions of the V-RQOL wasn't foudf in the literature, but it is relevant information that should be considered during the treatment of the dysphonic patient.

There was correlation of the V-RQOL scores with the voice self-perception, which is consistent with the results reported by Hogikyan and Sethuraman (1999) in the study that validated the V-RQOL in the assessment of patients with spasmodic dysphonia (Hogikyan et al. 2001). In these studies the V-RQOL proved to be sensible to the influence of dysphonia in the quality of life. This correlation between vocal self-perception and V-RQOL showed that the higher the score on the V-RQOL the better the opinion about his/her own voice. Using other method to assess the impact of the vocal disorder in the life of the dysphonic patient, Ma and Yiu (2001) found correlation of vocal self-perception and the other sessions of the VAAP (Voice Activity and Participation Profile) that refer to effects in work, daily communication, social communication and emotion. Despite not having used the specific protocol of quality of life, Köhle et al. (2004) found correlation between vocal self evaluation and dysphonia while studying correlations between vocal self-evaluation through visual analogical scale, complaints and speechpathology auditory-perceptive and acoustic evaluation and assessing the profile of the population included on a program of vocal health protection. It was observed that there was correlation between vocal self-evaluation and vocal disorder that is, subjects with poorer scores on self-evaluation had vocal disorders.

It was also found correlation between the domains of the V-RQOL that is, the higher the score on the socio-emotional domain the higher the score on the physical domain (the opposite is also true), consequently resulting on a higher total score.

There was no correlation of the judges' opinions and vocal self-perception. Similar data was found in the study by Ma and Yiu (2001) where self perception of the severity of voice disorder (VAAP's 
session 1) had small correlation with the dysphonia's severity acoustically and perceptively measured by speech pathologists judges.

There were no correlations of the V-RQOL's scores and the non-trained listeners' opinions. Eadie and Doyle (2004) conducted a study with tracheo-esophagic speakers and found positive correlations between the results of a protocol of quality of life (HNQOL - Head and Neck Quality of Life) and the opinion of un-trained judges. Never the less, this correlation may have been influenced by the higher degree of vocal quality impairment of tracheo-esophagyc speakers.

Based on the results found in this study we can say the dysphonic's patient's opinion about the impact of the dysphonia on his/her quality of life corresponds to the vocal self perception but not to the opinion of un-trained listeners.

\section{References}

BEHLAU, M.; AZEVEDO, R.; PONTES, P. Conceito de voz normal e classificação das disfonias. In: BEHLAU, M. Voz: o livro do especialista, 1. Rio de Janeiro: Revinter, 2001a. cap. 2, p. 53-79.

BEHLAU, M.; MADAZIO, G.; FEIJÓ, D.; PONTES, P. Avaliação de voz. In: BEHLAU, M. Voz: o livro do especialista, 1. Rio de Janeiro: Revinter, 2001b. cap. 3, p. 85-180.

BEHLAU, M.; FEIJÓ, D.; MADAZIO, G.; REHDER, M. I.; AZEVEDO, R.; FERREIRA, A. E. Voz profissional: aspectos gerais e atuação fonoaudiológica. In: BEHLAU, M. Voz: o livro do especialista, 2. Rio de Janeiro: Revinter, 2005, cap. 12, p. 287-372.

BELE, I. V. Reliability in perceptual analysis of voice quality. J. Voice, Mosby, v. 19, n. 4, p. 555-573, dez. 2005.

BENNINGER, M. S.; GARDNER, G.; GRYWALSKI, C. Outcomes of botulinum toxin treatment for patients with spasmodic dysphonia. Arch. Otolaryngol. Head Neck Surg., Chicago, v. 127, n. 9, p. 1083-1085, set. 2001.

BERLIM, M. T.; FLECK, M. P. A. Quality of life: a brand new concept for research and practice in psychiatry. $R$. Bras. Psiquiatr., São Paulo, v. 25, n. 4, p. 249-252, 2003.

BERRETIN, G.; AVELAR, J. A.; MOLINA, K. L.; CRISTOVAM, L. S.; BRASOLOTTO, A. G.; MARTINS, C. H. Modelo alternativo de atendimento fonoaudiológico voltado aos distúrbios da voz. In: FERREIRA, L. P.; COSTA, H. O. (Org.). Voz ativa: falando sobre a clínica fonoaudiológica. São Paulo: Roca, 2001. p. 1-9.

\section{Conclusion}

The answering of the V-RQOL protocol, including self-evaluation of quality of life by 31 dysphonic individuals and the judgment of their voices by un-trained judges allowed the conclusions:

. the higher the scores on V-RQOL either total or in the physical and socio-emotional domains or in the better the vocal self-perception of the dysphonic individuals;

. there was no correlation between results on the V-RQOL and the opinion of dysphonic subjects' voice quality by un-trained listeners.
CARELLI, E. G.; NAKAO, M. Educação vocal na formação do docente. Fono Atual, São Paulo, ano 5, n. 22, p. 40-52, 2002.

DEARY, I. J.; WILSON J. A.; CARDING, P. N.; MACKENZIE, K. VoiSS: a patient-derived, Voice Symptom Scale. J. Psychos. Res., v. 54, p. 483-489, 2003 a.

DEARY, I. J.; WILSON, J. A.; CARDING, P. N.; MACKENZIE, K. The dysphonic voice heard me, you and it: differential associations with personality and psychological distress. Clin. Otolaryngol., Oxford, v. 23, p. 374-378, 2003b.

DEJONCKERE, P. H.; BRADLEY, P.; CLEMENTE, P.; CORNUT, G.; CREVIER-BUCHMAN, L.; FRIEDRICH, G.; HEYNING, V. DE P.; REMACLE, M.; WOISARD, V. A basic protocol for functional assessment of voice pathology, specially for investigating the efficacy of (phonosurgical) treatments and evaluating new assessment techniques: guideline elaborated by the Committee on Phoniatrics of the European Laryngological Society (ELS). Eur. Arch. Othorhinolaryngol., Heildelberg, v. 258, p. 77-82, 2001.

EADIE, T. L.; DOYLE, P. C. Auditory-perceptual scaling and quality of life in tracheoesophageal speakers. Laryngosc., Philadelphia, v. 114, n. 4, p. 753-759, abr. 2004.

FERREIRA, L. P. A voz do professor: uma proposta de promoção de saúde vocal. In: GIROTO, C. R. M. Perspectivas atuais da fonoaudiologia. São Paulo: Plexus, 2001, cap. 5, p. 73-89. 
FERREIRA, L. P.; GIANNINI, S. P. P.; FIGUEIRA, S.; SILVA, E. E.; KARMANN, D. de F.; SOUZA, T. M. T. de. Condições de produção de saúde vocal de professores da prefeitura do município de São Paulo. Dist. Comun., São Paulo, v. 14, n. 2, p. 275-307, jun. 2003.

GLIKLICH, R. E.; GLOVSKY, R. M.; MONTGOMERY, W. M. Validation of a outcome survey for unilateral vocal cord paralysis. Otolaryngol. Head Neck Surg., Mosby, v. 120, n. 2, p. 153-158, fev. 1999.

GRILLO, M. H. M. M.; PENTEADO, R. Z. Impacto da voz na qualidade de vida de professores (as) do ensino fundamental. Pró-fono R. Atual. Cient., Barueri (SP), v. 17, n. 3, p. 321-330, dez. 2005.

HARTNICK, C. J. Validation of a pediatric voice qualityof-life instrument: the pediatric voice outcome survey. Arch. Otolaryngol. Head Neck Surg., Chicago, v. 128, n. 8, p. 919-922, ago. 2002.

HOGIKYAN, N. D.; ROSEN, C. A. A review of outcome measurements for voice disorders. Otolaryngol. Head Neck Surg., Mosby, v. 126, n. 5, p. 562-572, maio 2002.

HOGIKYAN, N. D.; SETHURAMAN, G. Validation of an instrument to measure voice-related quality of life (V-RQOL). J. Voice, Mosby, v. 13, n. 4, p. 557-569, dez. 1999.

HOGIKYAN, N. D.; WODCHIS, W. P.; SPAK, C.; KILENY, P. R. Longitudinal effects of botulinum toxin injections on voice related quality of life (V-RQOL) for patients with adductory spasmodic dysphonia. J. Voice, Mosby, v. 15, n. 4, p. 576-586, dez. 2001.

JACOBSON, B. H.; JOHNSON, A.; GRYWALSKI, C.; SILBERGLEIT, A.; JACOBSON, G.; BENNINGER, M. S.; NEWMAN, C. W. The voice handicap index: development and validation. Am. J. Speech Lang. Pathol., Rockville, v. 6, n. 3, p. 66-70, ago. 1997.

KÖHLE, J.; NEMR, K.; LEITE, G. C. A.; SANTOS, A. O.; LEHN, C. N.; CHEDID, H. M. Ação de proteção de saúde vocal: perfil da população e correlação entre autoavaliação vocal, queixas e avaliação fonoaudiológica perceptivo-auditiva e acústica. Dist. Com., São Paulo, v. 16, n. 3, p. 333-341, dez. 2004.

MA, E. P.; YIU, E. M. Voice activity and participation profile: assessing the impact of voice disorders on daily activities. J. Speech Lang. Hear. Res., Rockville, v. 44, n. 3 , p. 511-524, jun. 2001
MELECA, R. J.; DWORKIN, J. P.; KEWSON, D. T.; STACHLER, R. J.; HILL, S. L. Functional outcomes following nonsurgical treatment for advanced-stage laryngeal carcinoma. Laryngosc., Philadelphia, v. 113, n. 4, p. 720728, abr. 2003.

MURRY, T.; MEDRADO, R.; HOGIKYAN, N. D.; AVIV, J. E. The relationship between ratings of voice quality and quality of life measures. J. Voice, Mosby, v. 18, n. 2, p. 183-192, jun. 2004.

PENTEADO, R. Z. Aspectos de qualidade de vida e de subjetividade na promoção da saúde vocal do professor. 2003. 227 f. Tese (Doutorado em Saúde Pública) - Faculdade de Saúde Pública, Universidade de São Paulo, São Paulo.

PINHO, S. M. R. Definições e classificação vocal. In: PINHO, S. M. R. Fundamentos em fonoaudiologia: tratando os distúrbios da voz. Rio de Janeiro: Guanabara Koogan, 2003. p. 3-7.

SCHWARZ, K.; CIELO, C. A. A voz e as condições de trabalho de professores de cidades pequenas do Rio Grande do Sul. R. Soc. Bras. Fonoaudiol., São Paulo, v. 10, n. 2, p. 83-90, 2005.

SPECTOR, B. C.; NETTERVILlE, J. L.; BILLANTE, C.; CLARY, J.; REINISCH, L.; SMITH, T. L. Quality of life assessment in patients with unilateral vocal cord paralysis. Otolaryngol. Head Neck Surg., Mosby, v. 125, n. 3, p. 176-182, set. 2001.

THE WHOQOL GROUP 1995. The World Health Organization quality of life assessment (WHOQOL): position paper from the World Health Organization. Soc. Sci. Med., Oxford, v. 41, n. 10, p. 1403-1409, 1995.

WARE, J. E.; SHERBOURNE, C. D. The MOS 36-item short-form health survey (SF-36): I - conceptual framework and item selection. Med. Care, Hagerstown, v. 30, n. 6, p. 473-483, 1992.

WEINSTEIN, G. S.; EL-SAWY, M. M.; RUIZ, C.; DOOLEY, P.; CHALIAN, A.; EL-SAYED, M. M.; GOLDBERG, A. Laryngeal preservation with supracricoid partial laryngectomy results in improved quality of life when compared with total laryngectomy. Laryngosc., Philadelphia, v. 111, n. 2, p. 191-199, fev. 2001.

WILSON, J. A.; DEARY, I. J.; MILLAR, A.; MACKENZIE, K. The quality of life impact of dysphonia. Clin. Otolaryngol., Oxford, v. 7, p. 179-182, 2002. 